\title{
RSM-Based Preparation and Photoelectrocatalytic Performance Study of RGO/TiO 2 NTs Photoelectrode
}

\author{
Jinlong Zuo, Siying Yuan (), Yiwen Li, Chong Tan, Zhi Xia, Shaodong Yang, Shiyou Yu and Junsheng Li * \\ School of Food Science and Engineering, Harbin University of Commerce, Harbin 150028, China; \\ 101760@hrbcu.edu.cn (J.Z.); yyuansiying@163.com (S.Y.); 13946139321@163.com (Y.L.); \\ 102776@hrbcu.edu.cn (C.T.); $102820 @$ hrbcu.edu.cn (Z.X.); ysd1220@126.com (S.Y.); 102904@hrbcu.edu.cn (S.Y.) \\ * Correspondence: 101719@hrbcu.edu.cn; Tel.: +86-0451-84844281
}

check for updates

Citation: Zuo, J.; Yuan, S.; Li, Y.; Tan, C.; Xia, Z.; Yang, S.; Yu, S.; Li, J. RSM-Based Preparation and Photoelectrocatalytic Performance Study of RGO/ $\mathrm{TiO}_{2}$ NTs

Photoelectrode. Processes 2021, 9, 1492. https://doi.org/10.3390/pr9091492

Academic Editor: Xiaopeng Li

Received: 28 July 2021

Accepted: 16 August 2021

Published: 25 August 2021

Publisher's Note: MDPI stays neutral with regard to jurisdictional claims in published maps and institutional affiliations.

Copyright: (c) 2021 by the authors. Licensee MDPI, Basel, Switzerland. This article is an open access article distributed under the terms and conditions of the Creative Commons Attribution (CC BY) license (https:// creativecommons.org/licenses/by/ $4.0 /)$.

\begin{abstract}
In this paper, reduced graphene oxide (RGO) was prepared by a modified Hummers method and chemical reduction method, and an $\mathrm{RGO} / \mathrm{TiO}_{2} \mathrm{NTs}\left(\mathrm{RGO} / \mathrm{TiO}_{2}\right.$ nanotubes) photoelectrode was prepared by the electrochemical deposition method. The as-prepared $\mathrm{RGO} / \mathrm{TiO}_{2}$ NTs were analyzed by scanning electron microscopy (SEM) and X-ray diffraction (XRD), and their photocatalytic activities were investigated by measuring the degradation of methylene blue (MB) under simulated solar light irradiation. The SEM and XRD results indicated that the original tubular structure of $\mathrm{TiO}_{2}-\mathrm{NTs}$ was not changed after RGO modification. The surface of the $\mathrm{TiO}_{2} \mathrm{NTs}$ photoelectrode was covered with a non-uniform, flake-shaped reduced graphene oxide film. The thickness of the $\mathrm{RGO} / \mathrm{TiO}_{2} \mathrm{NTs}$ was increased to about $22.60 \mathrm{~nm}$. The impedance of the $\mathrm{RGO} / \mathrm{TiO}_{2} \mathrm{NTs}_{\text {was }}$ smaller than that of the $\mathrm{TiO}_{2} \mathrm{NT}$ photoelectrode. The optimal preparation conditions of $\mathrm{RGO} / \mathrm{TiO}_{2}$ NT photoelectrodes were investigated by using a single factor method and response surface method. The best preparation conditions were as follows: deposition potential at $1.19 \mathrm{~V}$, deposition time of $10.27 \mathrm{~min}$, and deposition temperature at $24.94{ }^{\circ} \mathrm{C}$.
\end{abstract}

Keywords: methylene blue; photoelectrocatalysis; response surface method; $\mathrm{RGO} / \mathrm{TiO}_{2} \mathrm{NTs}$

\section{Introduction}

In recent years, the discharge of a large amount of dye wastewater has caused a huge threat to the environment, due to the toxicity, mutagenicity and carcinogenicity of dyes [1,2]. Among various dyes, methylene blue is one of the most common pollutants to prevent wastewater [3]. In terms of ecological environment, MB blocks sunlight from penetrating the water body, thereby posing a threat to aquatic life; in terms of public health, MB may burn eyes and cause irreversible damage [4]. Therefore, it is extremely necessary to remove dyes in wastewater. Commonly used methods for removing dyes include biosorption, electrocoagulation, redox, photocatalysis, etc. [5-9]. Photoelectrocatalysis (PEC) is an electrochemical advanced oxidation process (EAOP) combining photocatalysis with electrolysis [10]. Considering the renewable source of solar energy, research on photocatalysis has been rapidly expanding in recent years [11]. However, compared with photocatalysis, PEC can effectively solve the problem of the recombination of photogenerated electronhole pairs in photocatalysis, so it has been widely used in the removal of pollutants in wastewater in recent years $[12,13]$.

In 1972, Fujishima and Honda et al. [14] found that water could be decomposed into $\mathrm{H}_{2}$ and $\mathrm{O}_{2}$ by the $\mathrm{TiO}_{2}$ photoelectrode under light conditions. Since then, $\mathrm{TiO}_{2}$ has been thought to be an ideal semiconductor close to photocatalysis due to its high stability, low cost, harmlessness, high electron mobility, and excellent photoactivity [15-17]. However, $\mathrm{TiO}_{2}$ has a wide band gap (3.0 3.2 eV) [18]. Therefore, it is slightly difficult to use sunlight as an external light source for catalytic titanium dioxide. This limitation can be overcome by changing the form of titanium dioxide or doping with other materials. $\mathrm{TiO}_{2}$ nanotubes have been proven to have great research potential in photoelectric decomposition, 
optoelectronics, photocatalysis, and sensors [19-24]. Compared with all other forms of $\mathrm{TiO}_{2}, \mathrm{TiO}_{2}$ nanotubes show higher stability in morphology, structure, and photoelectric degradation performance $[25,26]$. In order to improve the photoelectric catalytic activity of $\mathrm{TiO}_{2}$, researchers have carried out a large number of modification studies. The main methods include non-metallic element doping, precious metal deposition, and semiconductor compounding. Dandan Cao et al. [27] synthesized Ag-AgBr nanospheres on the tubular surface of $\mathrm{TiO}_{2}$ nanotube arrays $\left(\mathrm{TiO}_{2} \mathrm{NTA} / \mathrm{Ag}-\mathrm{AgBr}\right)$. Due to the sensitization of $\mathrm{Ag}-\mathrm{AgBr}$ nanospheres, the visible light response region was significantly extended and the photoelectric conversion activity was improved. The visible photovoltage and transient photocurrent density of the $\mathrm{TiO}_{2} \mathrm{NTA} / \mathrm{Ag}-\mathrm{AgBr}(0.025)$ photoelectrode were -0.17 volts and $0.12 \mathrm{~mA} / \mathrm{cm}^{2}$. Maryline et al. [28] prepared $\mathrm{RGO} / \mathrm{TiO}_{2}$ nanofibers as photocatalytic materials and used the degradation rate of methyl orange to observe its catalytic efficiency. The results showed that the reaction rate of $\mathrm{RGO} / \mathrm{TiO}_{2}(2 \mathrm{wt} . \%)$ nanofibers was significantly higher than that of commercial $\mathrm{TiO}_{2}-\mathrm{P} 25$. Yuyuan Zhang et al. [29] introduced visible light-activated cadmium sulfide flowers onto the titanium dioxide nanotube array film on the titanium foil substrate to effectively separate the photo-excited electron-hole pairs and to improve the photocatalytic efficiency and water splitting in photoelectrochemical conversion, and the yield of hydrogen production. The excellent enhancement effect of graphene oxide nanosheets on the photocatalytic performance of $\mathrm{TiO}_{2}$ was attributed to its thin two-dimensional sheet support, large specific surface area, greatly increased adsorption capacity, and a good electron acceptor favoring the transfer of photo-generated electrons from the conduction band of $\mathrm{TiO}_{2}$ to the graphene oxide sheet [30-32]. The above qualities make graphene oxide nanosheets one of the candidate materials in the effort to improve the catalytic activity of titanium dioxide [33].

Response surface methodology (RSM) comprises a set of mathematical and statistical techniques based on polynomial equation fitting with experimental data, which describes the behavior of data sets and aims at statistical prediction. It is suitable for optimizing system performance when one or more responses are affected by several variables [34]. Box and Behnken et al. [35] suggested how to select points from a three-level factorial arrangement, which allows the efficient estimation of the first- and second-order coefficients of the mathematical model. These designs are more efficient and economical, particularly for a large number of variables.

In order to improve the visible light photocatalytic activity of $\mathrm{TiO}_{2} \mathrm{NT}$ photoelectrode, RGO was loaded onto the electrode. Due to the strong carrier mobility, optical transparency, and flexibility of sp2 hybrid graphene, it is currently used in many fields, such as photocatalysis, sensors, and solar materials. In this experiment, the response surface experiment was designed. $\mathrm{RGO}$ was deposited onto $\mathrm{TiO}_{2} \mathrm{NTs}$ by the electrochemical deposition method, and the samples were analyzed by SEM, EDS, XRD, and Raman. The photoelectrocatalytic properties of $\mathrm{RGO} / \mathrm{TiO}_{2} \mathrm{NTs}$ photoelectrode materials under external light were studied, which can provide a reference for the preparation of high-performance photoelectrocatalytic materials.

The purpose of this study is to deposit $\mathrm{RGO}$ onto $\mathrm{TiO}_{2}$ NTs by electrochemical deposition, and to study the effect of active free radicals on the photocatalytic oxidation reaction and the stability of the photoelectrode. The specific objectives are as follows: (1) to prepare $\mathrm{TiO}_{2}$ NTs photoelectrode material by anodizing method; (2) to prepare RGO by a modified Hummers method and chemical reduction method, and prepare an $\mathrm{RGO} / \mathrm{TiO}_{2} \mathrm{NT}$ photoelectrode by the electrochemical deposition method; (3) to optimize the $\mathrm{RGO} / \mathrm{TiO}_{2} \mathrm{NT}$ photoelectrode. This achievement is considered to provide a theoretical basis and reference for the preparation of high-performance catalytic materials.

\section{Materials and Methods}

\subsection{Materials}

Reagents: $\mathrm{C}, \mathrm{P}_{2} \mathrm{O}_{5}, \mathrm{~K}_{2} \mathrm{~S}_{2} \mathrm{O}_{8}, \mathrm{CH}_{3} \mathrm{COOH}, \mathrm{KI}, \mathrm{K}_{2} \mathrm{Cr}_{2} \mathrm{O}_{7}, \mathrm{KMnO}_{4}, \mathrm{NH}_{3} \cdot \mathrm{H}_{2} \mathrm{O}, \mathrm{N}_{2} \mathrm{H}_{4} \cdot \mathrm{H}_{2} \mathrm{O}$, $\mathrm{Na}_{2} \mathrm{SO}_{4}$. 
Instruments: Desktop high-speed centrifuge (Shanghai Luxiang Instrument Co., Ltd., Harbin, China), Raman spectrometer (HORIBA Jobin Yvon, Harbin, China).

\subsection{Synthesis of $\mathrm{RGO} / \mathrm{TiO}_{2} \mathrm{NTS}$}

\subsubsection{Synthesis of GO}

Graphene oxide (GO) was prepared by a modified Hummers method. Firstly, graphite powder $(1 \mathrm{~g})$ was treated with $80 \mathrm{~mL} \mathrm{H}_{2} \mathrm{SO}_{4}, 1 \mathrm{~g} \mathrm{~K}_{2} \mathrm{~S}_{2} \mathrm{O}_{4}, 1 \mathrm{~g} \mathrm{P}_{2} \mathrm{O}_{5}$ and slowly heated to $80{ }^{\circ} \mathrm{C}$ for $5 \mathrm{~h}$. Then, a large amount of deionized water was used to wash repeatedly until it was neutral to obtain pre-graphite oxide, and the pre-oxidized graphite was dried at $6{ }^{\circ} \mathrm{C}$ for $12 \mathrm{~h}$. A mixture of $40 \mathrm{~mL} \mathrm{H}_{2} \mathrm{SO}_{4}$ and graphite was added to the ice water bath in the flask. Secondly, $4 \mathrm{~g} \mathrm{KMnO}$ was slowly added to the solution, heated to $35^{\circ} \mathrm{C}$ to react for $2 \mathrm{~h}$. Then, deionized water was added and heated to about $98^{\circ} \mathrm{C}$. After $15 \mathrm{~min}$, deionized water and $10 \mathrm{~mL} \mathrm{H}_{2} \mathrm{O}_{2}$ were added and then centrifuged when the color of the solution gradually changed into golden yellow. The obtained solid was washed with dilute hydrochloric acid and deionized water to remove residual acid on the surface. Finally, the GO sample was dried by vacuum at $60^{\circ} \mathrm{C}$ for $12 \mathrm{~h}$.

\subsubsection{Synthesis of RGO}

RGO was prepared by the chemical reduction method. Graphene oxide (GO) was added to deionized water and ultrasonically treated for $1 \mathrm{~h}$. Ammonia was added and the $\mathrm{pH}$ was adjusted to 10 . A total of $250 \mathrm{~mL}$ hydrazine hydrate (35\%) was added to the treated GO and heated at $95^{\circ} \mathrm{C}$ for $4 \mathrm{~h}$. The black solution was filtered, followed by washing with dilute hydrochloric acid and deionized water to remove residual acid on the surface. RGO was obtained by vacuum drying at $70^{\circ} \mathrm{C}$ for $12 \mathrm{~h}$.

\subsubsection{Fabrication Method of $\mathrm{RGO} / \mathrm{TiO}_{2} \mathrm{NTs}$}

In this study, a $\mathrm{TiO}_{2} \mathrm{NT}$ photoelectrode grown on Ti foils was prepared by the anodic oxidation method, and the synthesis progress and experiment parameters are provided in our previous papers [36]. The $\mathrm{RGO} / \mathrm{TiO}_{2} \mathrm{NTs}$ photoelectrode was prepared by electrochemical deposition. The electrodeposition solution was a mixture of $100 \mathrm{mg} \cdot \mathrm{L}^{-1} \mathrm{RGO}$ solution and $0.5 \mathrm{~mol} \cdot \mathrm{L}^{-1} \mathrm{Na}_{2} \mathrm{SO}_{4}$. A three-electrode system was adopted with the $\mathrm{TiO}_{2}$ NTs electrode as the anode, Pt as the cathode, and SEC as the reference electrode. Electrodeposition was conducted at a certain voltage for a period of time. After the reaction was completed, the sample was repeatedly rinsed with deionized water and then vacuum dried at $70{ }^{\circ} \mathrm{C}$ for $4 \mathrm{~h}$. Finally, the $\mathrm{RGO} / \mathrm{TiO}_{2} \mathrm{NTs}$ was obtained.

\subsection{Photoelectric Catalytic Activity Tests}

The photoelectric catalytic property of $\mathrm{RGO} / \mathrm{TiO}_{2} \mathrm{NT}$ photoelectrode was evaluated by photoelectric catalytic oxidation degradation of $5 \mathrm{mg} / \mathrm{L}$ methylene blue aqueous solution. At room temperature, $80 \mathrm{~mL}$ methylene blue solution was added to a $100 \mathrm{~mL}$ quartz beaker. The mercury lamp was used as the external light source and placed parallel to the Ti sheet, with an interval of $10 \mathrm{~cm}$. The $35 \mathrm{~W}$ external light source and the $15 \mathrm{~V}$ DC regulated power supply were turned on. At regular intervals of $30 \mathrm{~min}$, a $5 \mathrm{~mL}$ sample was taken and the absorbance was checked at $664 \mathrm{~nm}$ through a UV-vis spectrophotometer. The degradation efficiency $(\eta)$ was calculated using the following equation:

$$
\eta=\frac{C_{0}-C_{t}}{C_{0}} \times 100 \%
$$

where $C_{0}$ is the initial concentration of $\mathrm{MB}(\mathrm{mg} / \mathrm{L})$ and $C_{t}$ is the instantaneous concentrations $(\mathrm{mg} / \mathrm{L})$ in the solution.

\subsection{Single Factor Test}

Single factor test was used to design the photoelectric catalytic performance experiments of $\mathrm{RGO} / \mathrm{TiO}_{2} \mathrm{NTs}$ photoelectrodes. The deposition potential, deposition time, and 
deposition temperature were taken as research targets. The voltages were $0.6,0.8,1.0,1.2$, and $1.4 \mathrm{~V}$, the deposition times were $4,6,8,10$, and $12 \mathrm{~min}$, and the deposition temperatures were $15,20,25,30$, and $35^{\circ} \mathrm{C}$, respectively.

\subsection{Response Surface Experimental Design}

RSM was used to regulate and control the photoelectric catalytic performance of $\mathrm{RGO} / \mathrm{TiO}_{2}$ NTs photoelectrodes. Box-Behnken with the software Design Expert 8.0 was employed to evaluate the combined effects of the three independent variables: deposition potential, deposition time, and deposition temperature. The coded and actual values of the three independent variables together with the responses are shown in Table 1.

Table 1. The design of RSM and the corresponding experimental and predicted values.

\begin{tabular}{|c|c|c|c|c|c|c|c|c|}
\hline \multirow{2}{*}{ Run } & \multicolumn{2}{|c|}{ Deposition Potential/V } & \multicolumn{2}{|c|}{ Deposition Time/min } & \multicolumn{2}{|c|}{$\begin{array}{c}\text { Deposition } \\
\text { Temperature } /{ }^{\circ} \mathrm{C}\end{array}$} & \multicolumn{2}{|c|}{ MB Degradation Rate (\%) } \\
\hline & A & Code & B & Code & $\mathrm{C}$ & Code & Experimental & Predicted \\
\hline 1 & 1.4 & 1 & 10 & 0 & 20 & -1 & 51.2 & 46.87 \\
\hline 2 & 1.4 & 1 & 8 & -1 & 25 & 0 & 51.2 & 52.15 \\
\hline 3 & 1 & -1 & 8 & -1 & 25 & 0 & 47.9 & 55.45 \\
\hline 4 & 1.2 & 0 & 10 & 0 & 25 & 0 & 65.8 & 49.63 \\
\hline 5 & 1.2 & 0 & 10 & 0 & 25 & 0 & 64.1 & 54.14 \\
\hline 6 & 1.2 & 0 & 10 & 0 & 25 & 0 & 66.5 & 49.66 \\
\hline 7 & 1 & -1 & 10 & 0 & 20 & -1 & 54.7 & 50.84 \\
\hline 8 & 1.2 & 0 & 10 & 0 & 25 & 0 & 64.9 & 53.76 \\
\hline 9 & 1.4 & 1 & 10 & 0 & 30 & 1 & 53.2 & 52.79 \\
\hline 10 & 1 & -1 & 12 & 1 & 25 & 0 & 56.4 & 58.61 \\
\hline 11 & 1.2 & 0 & 10 & 0 & 25 & 0 & 65.4 & 56.49 \\
\hline 12 & 1.2 & 0 & 8 & -1 & 30 & 1 & 58 & 55.71 \\
\hline 13 & 1.2 & 0 & 8 & -1 & 20 & -1 & 52.2 & 65.34 \\
\hline 14 & 1.4 & 1 & 12 & 1 & 25 & 0 & 49.6 & 65.34 \\
\hline 15 & 1 & -1 & 10 & 0 & 30 & 1 & 49.3 & 65.34 \\
\hline 16 & 1.2 & 0 & 12 & 1 & 20 & -1 & 57.1 & 65.34 \\
\hline 17 & 1.2 & 0 & 12 & 1 & 30 & 1 & 56.3 & 65.34 \\
\hline
\end{tabular}

\section{Results and Discussion}

\subsection{Analysis of Single Factor Test Results}

The $\mathrm{RGO} / \mathrm{TiO}_{2}$ NTs photoelectrode was prepared by depositing for $10 \mathrm{~min}$ with different deposition potentials and then used for photoelectric catalytic degradation of $\mathrm{MB}$, as shown in Figure 1. It was found that the catalytic effect of the photoelectrode on MB was significantly improved, showing a trend of first increasing and then decreasing. When the voltage was $1.2 \mathrm{~V}$, the photoelectrode had the best degradation effect on $\mathrm{MB}$, and the degradation rate reached $65.7 \%$. This may be due to the high deposition potential and to a large amount of RGO deposited on the surface of the nanotubes, which reduces the light absorption performance (Figure 1).

When the deposition potential is $1.2 \mathrm{~V}$, the photoelectric catalytic degradation effect of $\mathrm{RGO} / \mathrm{TiO}_{2} \mathrm{NTs}$ photoelectrode on $\mathrm{MB}$ is studied under different times. It can be seen from Figure 2 that when the deposition time is $10 \mathrm{~min}$, the photoelectric catalytic degradation effect is the best, and the MB degradation rate reaches $66.1 \%$. However, a longer deposition time causes too much RGO to accumulate on the surface of the nanotubes, which reduces the light absorption performance, resulting in a decrease in the degradation rate of $\mathrm{MB}$ (Figure 2). 


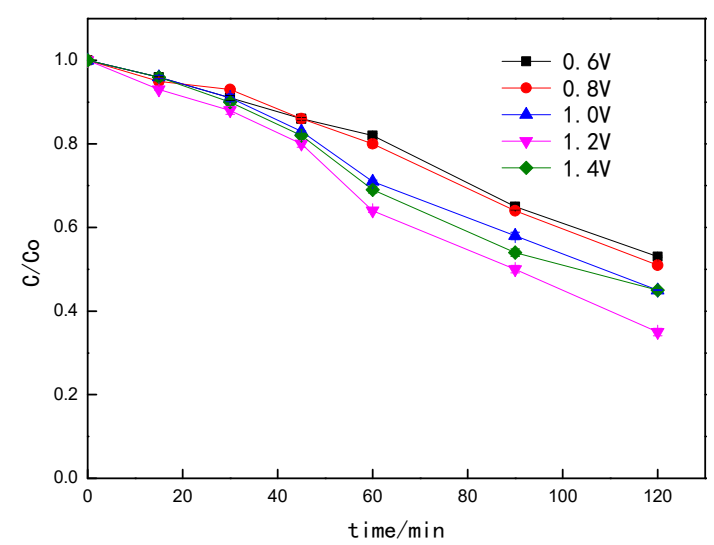

Figure 1. Effect of deposition voltages on the methylene blue degradation.

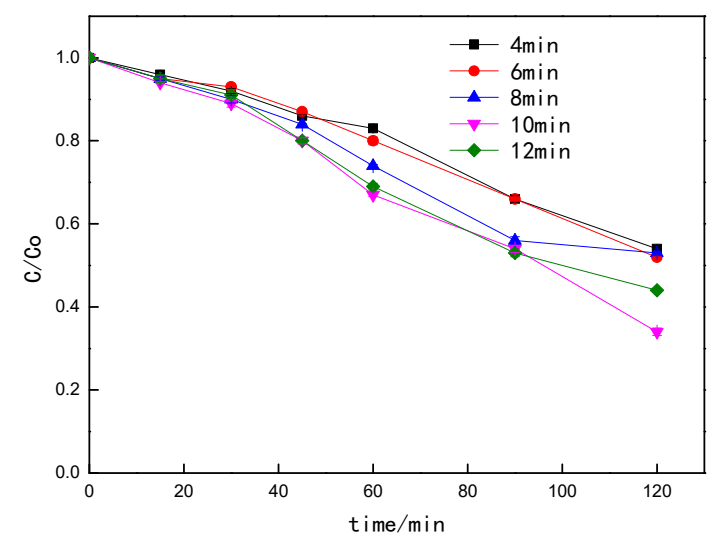

Figure 2. Effect of deposition time on the methylene blue degradation.

When the deposition potential was $1.2 \mathrm{~V}$ and the deposition time was $10 \mathrm{~min}$, the photoelectrodes were prepared under the conditions of different deposition temperatures. As shown in Figure 3, the photoelectric catalytic performance of the photoelectrode is proportional to the deposition temperature. When the deposition temperature was $25^{\circ} \mathrm{C}$, the photoelectric catalytic performance was at its best, and the degradation rate of $\mathrm{MB}$ reached $66.8 \%$. However, when the temperature rises further, the degradation of $\mathrm{MB}$ decreases. This may be due to a large amount of RGO accumulated on the surface of the nanotubes caused by the high temperature, which affects the photocatalytic activity (Figure 3).

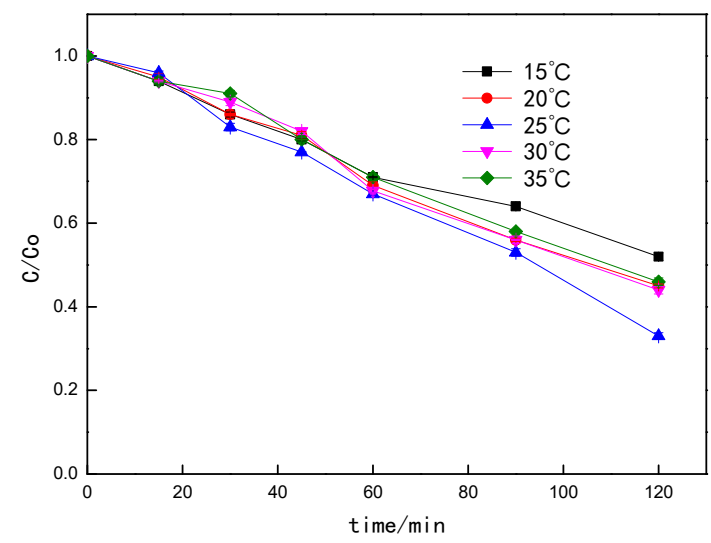

Figure 3. Effect of deposition temperature on the methylene blue degradation. 


\subsection{Optimization Conditions of $\mathrm{RGO} / \mathrm{TiO}_{2}$ NTs Production}

In the Equation (1), $\mathrm{Y}$ is the degradation rate of $\mathrm{MB}(\%)$, and $\mathrm{A}, \mathrm{B}, \mathrm{C}$ are the code values of deposition potential, deposition time, and deposition temperature. The positive and negative signs before each item represent synergistic and antagonistic effects. The model was evaluated based on the correlation coefficient $R^{2}$ The $R^{2}$ of the model is 0.9761 , which is close to 1 , indicating that the predicted value of the model was similar to the measured value. Table 1 showed the initial conditions of fermentation and the actual and predicted responses.

$$
\begin{gathered}
\mathrm{Y}=+65.34-0.39 \times \mathrm{A}+1.26 \times \mathrm{B}+0.20 \times \mathrm{C}-2.53 \times \mathrm{A} \times \mathrm{B}+1.85 \times \mathrm{A} \times \mathrm{C}-1.65 \times \mathrm{B} \times \mathrm{C} \\
-8.93 \times \mathrm{A}^{2}-5.13 \times \mathrm{B}^{2}-4.31 \times \mathrm{C}^{2}
\end{gathered}
$$

In the ANOVA results of RSM, shown in Table 2, those model terms with a " $p$-value" less than 0.05 were significant (Table 2). The model $p$-value was less than 0.0001 , which was extremely significant. The lack of fit was $0.0762(>0.05)$, which was not significant, indicating that the model fit well within the regression area. As the F-values in Table 2 show, the order of the impact of three conditions on $\mathrm{RGO} / \mathrm{TiO}_{2} \mathrm{NT}$ production was: $\mathrm{B}>\mathrm{A}>\mathrm{C}$. Moreover, the error statistical analysis of the regression equation showed that the $\mathrm{R}^{2}$ value was 0.9454 and $R_{a d j}{ }^{2}$ was 0.6900 , indicating that the $69 \%$ change in response value could be explained by the model. The precision was 15.193 , more than 4 , and proved reasonable; the CV was $2.64 \%$, less than $10 \%$, indicating the high reliability and accuracy of the test. The analysis results showed that the regression equation model was in good agreement with the actual test, which can effectively predict the test results. It is recommended to use this model to predict the optimal conditions for the preparation of $\mathrm{RGO} / \mathrm{TiO}_{2} \mathrm{NTs}$.

Table 2. ANOVA results of RSM.

\begin{tabular}{ccccccc}
\hline Source & Sum of Squares & Degree of Freedom & Mean of Square & F-Value & $p$-Value Prob $>$ F & Significant \\
\hline Model & 642.52 & 9 & 71.39 & 31.78 & $<0.0001$ \\
A & 1.2 & 1 & 1.2 & 0.53 & 0.4884 \\
B & 12.75 & 1 & 12.75 & 5.68 & 0.0487 \\
C & 0.32 & 1 & 0.32 & 0.14 & 0.7170 \\
AB & 25.5 & 1 & 25.5 & 11.35 & 0.0119 \\
AC & 13.69 & 1 & 13.69 & 6.09 & 0.0429 \\
BC & 10.89 & 1 & 10.89 & 4.85 & 0.0436 \\
A2 & 335.96 & 1 & 335.96 & 149.56 & $<0.0001$ \\
B2 & 110.92 & 1 & 110.92 & 49.38 & 0.0002 \\
C2 & 78.12 & 1 & 78.12 & 34.78 & 0.0006 \\
Residual & 15.72 & 7 & 2.25 & & 0.0762 \\
Lack of Fit & 12.43 & 3 & 4.14 & 5.04 & Not significant \\
Pure Error & 3.29 & 4 & 0.82 & & \\
Cor Total & 658.25 & 16 & & & \\
\hline
\end{tabular}

The regression equation can be effectively represented by the response surface threedimensional graph. The relationship between the response value of each variable and the test value is shown in Figure 4, which further evaluates the relationship between each variable and the best conditions. According to the analysis of Design Expert 8.0 software, the best preparation conditions for loading RGO onto $\mathrm{TiO}_{2} \mathrm{NTs}$ photoelectrodes were: deposition potential at $1.19 \mathrm{~V}$, deposition time of $10.27 \mathrm{~min}$, and deposition temperature at $24.94{ }^{\circ} \mathrm{C}$, and the predicted value of $\mathrm{MB}$ degradation rate was $65.43 \%$. Considering the actual situation, the optimal preparation conditions were identified as: deposition potential at $1.1 \mathrm{~V}$, deposition time of $10 \mathrm{~min}$, and deposition temperature at $25^{\circ} \mathrm{C}$ (Figure 4). 


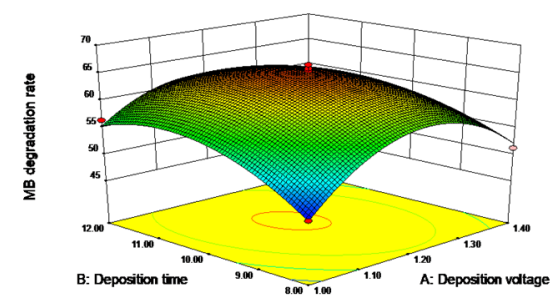

(a)

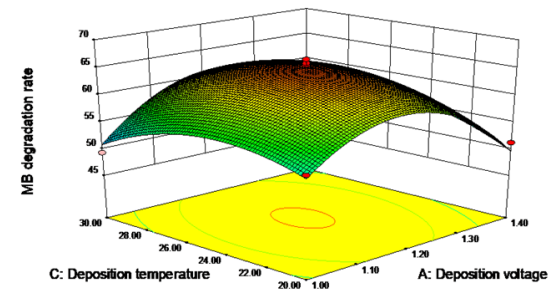

(b)

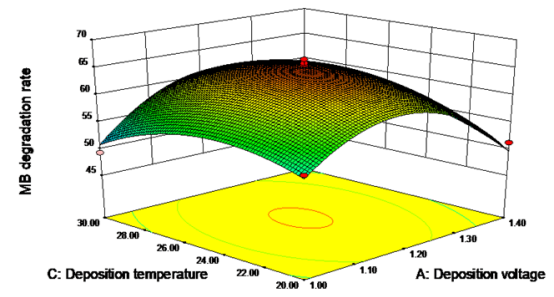

(c)

Figure 4. (a) Response Surface of deposition potential and deposition time to methylene blue degradation rate; (b) response surface of deposition potential and deposition temperature to methylene blue degradation rate; (c) response surface of deposition potential and deposition temperature to methylene blue degradation rate.

Figure 5 is the SEM image of the $\mathrm{RGO} / \mathrm{TiO}_{2}$ NT photoelectrode under the conditions of deposition potential of $1.1 \mathrm{~V}$, deposition time of $10 \mathrm{~min}$, and deposition temperature of $25^{\circ} \mathrm{C}$. It can be seen from the figure that after RGO modification, the surface of the $\mathrm{TiO}_{2}$ NTs photoelectrode was covered with a sheet of RGO film, which covered most of the nanotube surface. Part of the wall of the $\mathrm{RGO} / \mathrm{TiO}_{2}$ nanotube became thicker: measured by nano measurer 1.2.5, the wall was $22.60 \mathrm{~nm}$. Therefore, the $\mathrm{RGO} / \mathrm{TiO}_{2} \mathrm{NTs}$ photoelectrode had a better photoelectrocatalytic performance with RGO than without it (Figure 5).

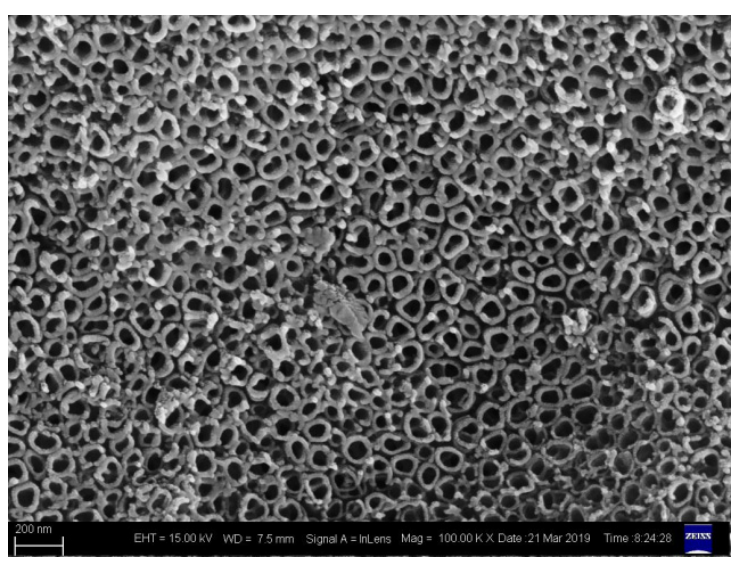

Figure 5. The SEM pattern of $\mathrm{RGO} / \mathrm{TiO}_{2} \mathrm{NT}$ photoelectrode.

Figure 6a is the XRD diffractogram of the photoelectrode prepared under the optimal preparation conditions. $\mathrm{Cu} K \alpha$ rays $(\lambda$ was $0.15418 \mathrm{~nm}$ ), the characteristic diffraction peak of anatase phase A (101), appeared when $2 \theta=25.3^{\circ}$, and the characteristic diffraction peak of rutile phase $\mathrm{R}(101)$ appeared when $2 \theta=27.4^{\circ}$. It can be seen from the figure that there were three crystal phases at the same time, and the diffraction peak position was the same as that of $\mathrm{TiO}_{2}$ NTs. After RGO modification, the characteristic diffraction peak of graphene (002) appeared at $2 \theta=24.9^{\circ}$, indicating that RGO had been successfully modified [37]. In order to further test whether RGO was successfully modified on the surface of the $\mathrm{TiO}_{2} \mathrm{NTs}$ photoelectrode, Raman spectroscopy was used. In the Raman spectrum of $\mathrm{TiO}_{2}$, the Raman peaks at $148,198,397,515$, and $638 \mathrm{~cm}^{-1}$ correspond to the anatase-induced $\mathrm{A}^{2} \mathrm{~g}^{+2} \mathrm{~B}_{\mathrm{g}}{ }^{+3} \mathrm{Eg}$ mode [38]. As shown in Figure 6b, the four Raman peaks caused by RGO are located at $1365,1585,2749$, and $2938 \mathrm{~cm}^{-1}$. This was caused by the $\mathrm{D}$ band related to the defects in the hexagonal graphite sheet and the G band related to the E2g mode. In addition, the $\mathrm{G}$ band was also related to the sp2 hybridized carbon atoms [39]. Therefore, it is further proved that RGO has been successfully modified on $\mathrm{TiO}_{2} \mathrm{NTs}$ (Figure 6). 


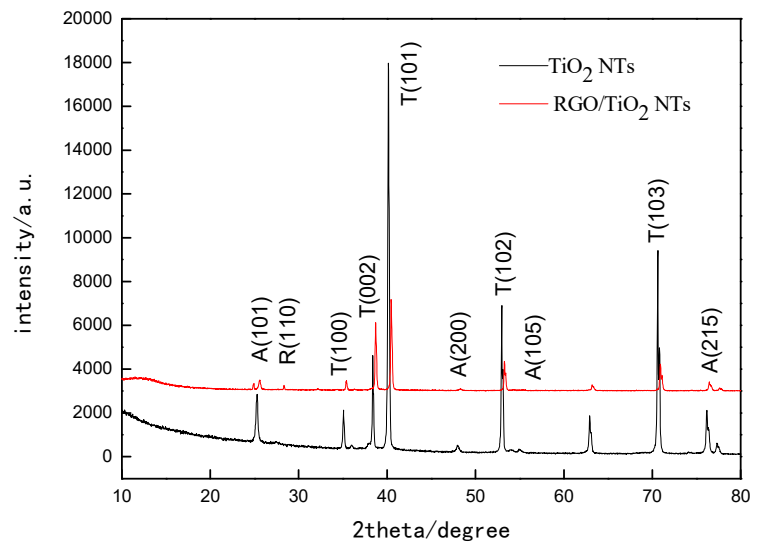

(a)

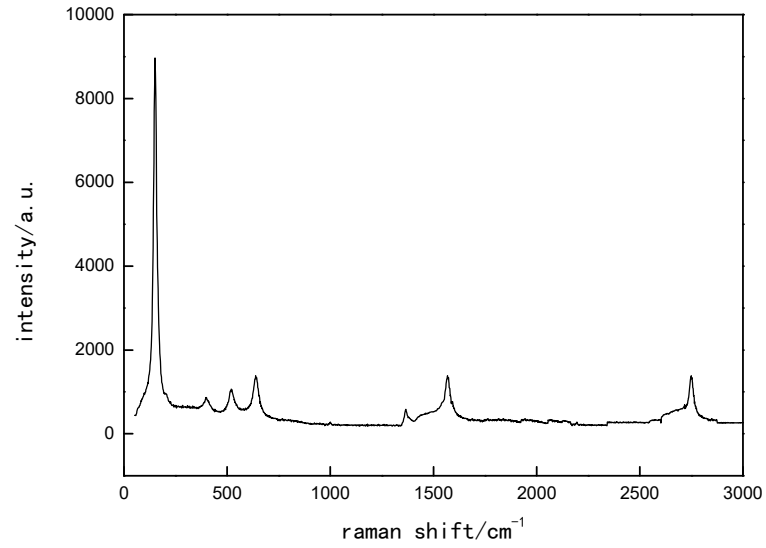

(b)

Figure 6. (a) XRD diffractogram of $\mathrm{RGO} / \mathrm{TiO}_{2}$ NTs photoelectrode; (b) XRD diffractogram and Raman spectrum of $\mathrm{RGO} / \mathrm{TiO}_{2}$ NTs photoelectrode.

In order to study the performance of $\mathrm{RGO} / \mathrm{TiO}_{2} \mathrm{NT}$ photoelectrodes prepared under the best conditions, the photoelectrocatalytic $\mathrm{MB}(80 \mathrm{~mL}, 5 \mathrm{mg} / \mathrm{L})$ degradation test was carried out under three different conditions, and the reaction time was $120 \mathrm{~min}$. As shown in Figure 7, when the electrode was illuminated by a $35 \mathrm{~W}$ mercury lamp, the photocatalytic degradation rate of $\mathrm{MB}$ was $17.2 \%$; when the electrode was protected from light under a $15 \mathrm{~V}$ bias voltage, the photocatalytic degradation efficiency of $\mathrm{MB}$ was $32 \%$; when the electrode was irradiated by a $35 \mathrm{~W}$ mercury lamp and a $15 \mathrm{~V}$ bias voltage was applied, the MB degradation efficiency was significantly increased to $64 \%$ (Figure 7).

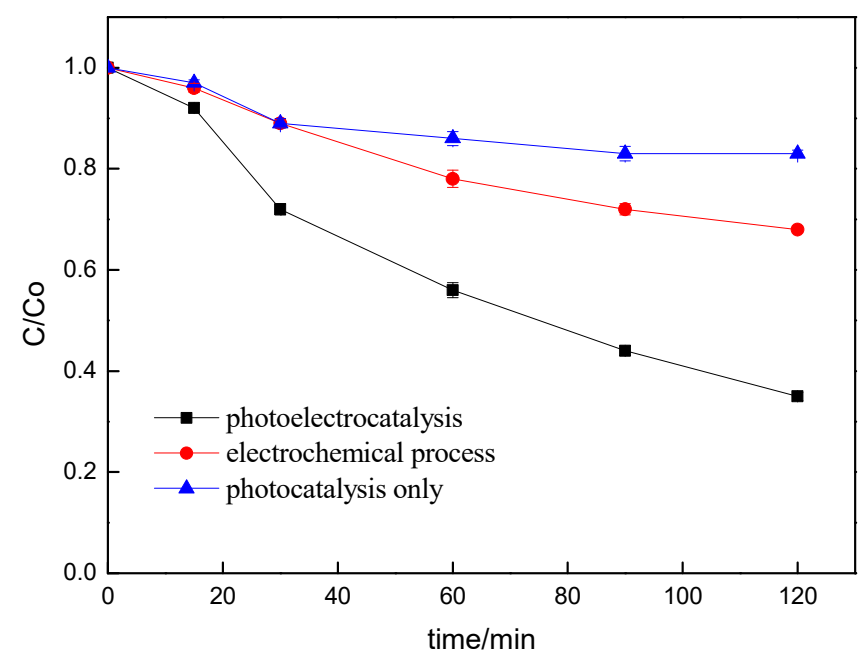

Figure 7. Degradation of methylene blue by $\mathrm{RGO} / \mathrm{TiO}_{2} \mathrm{NT}$ photoelectrode.

It can be seen from Figure 8 that the $\mathrm{MB}$ degradation rate of $\mathrm{TiO}_{2} \mathrm{NTs}$ photoelectrode under mercury lamp irradiation is $54 \%$, and the $\mathrm{MB}$ degradation rate under the catalysis of $\mathrm{RGO} / \mathrm{TiO}_{2} \mathrm{NTs}$ photoelectrode is $63 \%$, indicating that the degradation efficiency of the RGO modified $\mathrm{TiO}_{2}$ NTs photoelectrode has been significantly improved (Figure 8). 


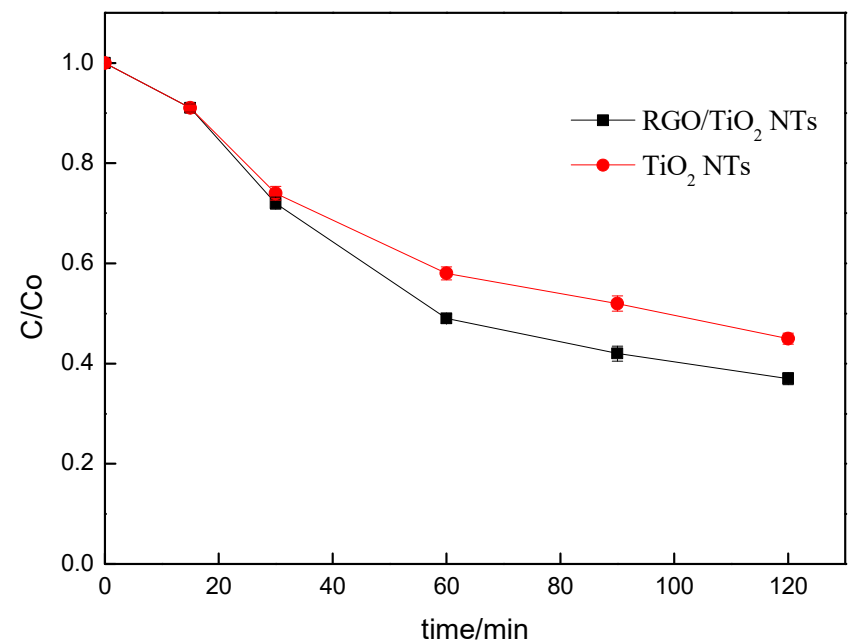

Figure 8. Photocatalytic degradation of methylene blue on $\mathrm{RGO} / \mathrm{TiO}_{2} \mathrm{NTs}$ and $\mathrm{TiO}_{2} \mathrm{NT}$ photoelectrode.

\subsection{Analysis of Photoelectrocatalytic Mechanism}

In the process of $\mathrm{RGO} / \mathrm{TiO}_{2}$ NTs photoelectrode photoelectrocatalysis of $\mathrm{MB}$, the active intermediates participating in the reaction mainly include $\cdot \mathrm{OH}, \mathrm{h}+$ and $\cdot \mathrm{O}_{2}{ }^{-} \mathrm{To}$ study the catalytic mechanism of $\mathrm{RGO} / \mathrm{TiO}_{2} \mathrm{NTs}$ photoelectrode to $\mathrm{MB}$, we conducted free radical scavenging experiments. It can be seen from Figure 9 that $\cdot \mathrm{OH}$ and $\mathrm{h}+$ are the main active substances in the photoelectric catalytic reaction.

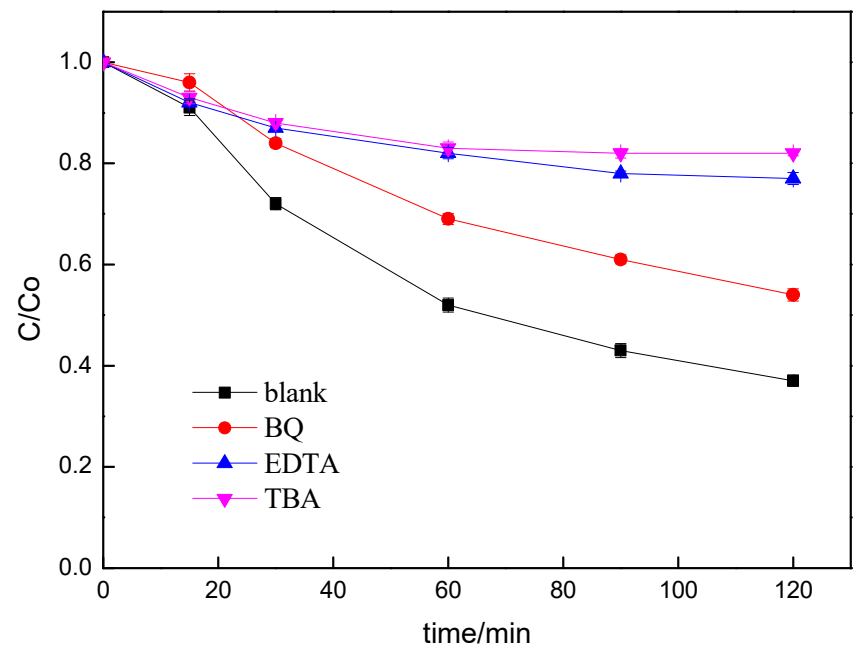

Figure 9. Effects of free radical scavengers on the degradation efficiency of methylene blue.

In order to study the stability of $\mathrm{RGO} / \mathrm{TiO}_{2} \mathrm{NTs}$ photoelectrode photoelectrocatalysis, a series of cyclic experiments were carried out. The result, as shown in Figure 10, was that the $\mathrm{RGO} / \mathrm{TiO}_{2} \mathrm{NTs}$ photoelectrode has excellent stability: after repeated use for five times, the degradation efficiency of MB was still above $58 \%$. 


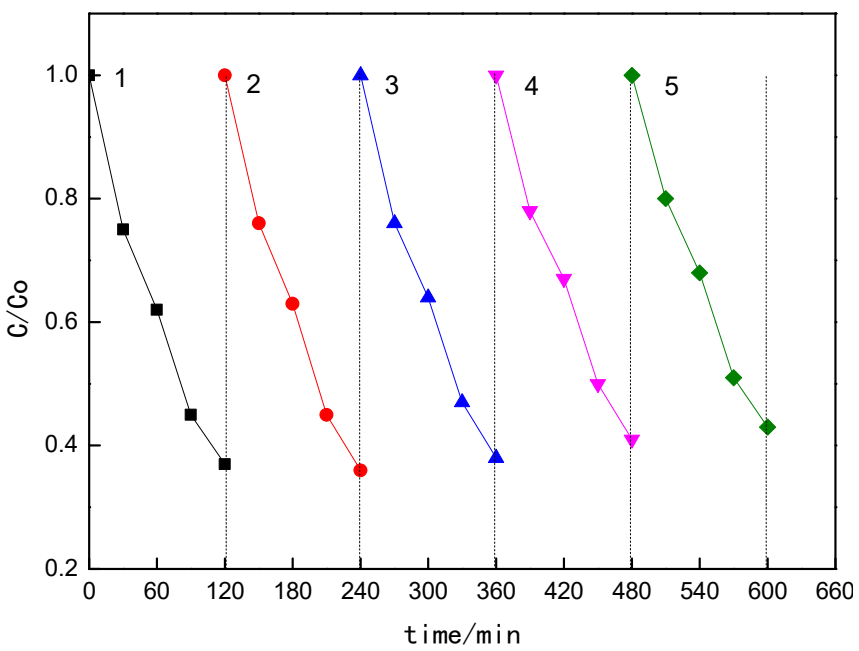

Figure 10. Stability study on $\mathrm{RGO} / \mathrm{TiO}_{2} \mathrm{NT}$ photoelectrode.

Figure 11 shows the catalytic activity mechanism of $\mathrm{RGO} / \mathrm{TiO}_{2} \mathrm{NTs}$ photoelectrodes. When light is irradiated, electrons in the valence band of $\mathrm{TiO}_{2}$ are excited to transition to the conduction band, leaving a hole in the valence band. At the same time, electrons in the valence band of RGO are excited to transition to the conduction band, also leaving holes in the valence band. Due to its good conductivity of RGO, it can promote the flow of photogenerated electrons from the conduction band of $\mathrm{TiO}_{2}$ to the conduction band of $\mathrm{RGO}$. These electrons can react with $\mathrm{O}_{2}$ to produce $\cdot \mathrm{O}_{2}{ }^{-}$. In addition, the holes in the conduction band of $\mathrm{TiO}_{2}$ and $\mathrm{RGO}$ can react with $\mathrm{H}_{2} \mathrm{O}$ to generate $\cdot \mathrm{OH}$. In this way, electrons are transferred to the conduction band of RGO to react with $\mathrm{O}_{2}$, and holes react with $\mathrm{H}_{2} \mathrm{O}$, effectively inhibiting the recombination of electrons and holes. Moreover, the applied voltage accelerates the migration rate of photo-generated electrons in the system, which greatly improves the photocatalytic effect. In addition, this method not only has excellent degradation effects but also has a simple process and is easy to characterize compared with photocatalytic oxidation reactions.

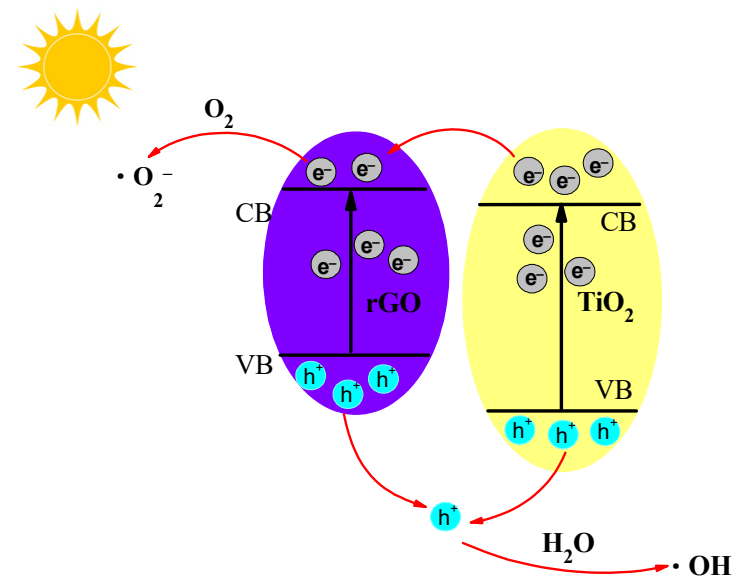

Figure 11. Photoelectric catalytic mechanism diagram.

\section{Conclusions}

Through single factor experiments, the optimal preparation conditions for $\mathrm{RGO} / \mathrm{TiO}_{2}$ NTs were found to be: deposition voltage at $1.1 \mathrm{~V}$, deposition time of $10 \mathrm{~min}$, and deposition temperature at $25^{\circ} \mathrm{C}$. According to the analysis and optimization of the response surface experiment design, the significance of the catalytic activity of $\mathrm{RGO} / \mathrm{TiO}_{2} \mathrm{NTs}$ photoelectrode was in the order of deposition time $>$ deposition voltage $>$ deposition temperature. The optimal preparation conditions obtained by optimization were: deposition voltage at 
$1.19 \mathrm{~V}$, deposition time of $10.27 \mathrm{~min}$, and deposition temperature at $24.94{ }^{\circ} \mathrm{C}$. The predicted value of MB degradation rate was $65.43 \%$. Compared with the actual value $(63 \%)$, the error value was $2.43 \%$, indicating that the preparation parameters optimized by RSM have practical application value. The results provide a reference for the large-scale application of $\mathrm{RGO} / \mathrm{TiO}_{2} \mathrm{NTs}$ photoelectrodes in engineering. Through SEM and XRD characterization analysis, it can be seen that after RGO modification, the original tubular structure of $\mathrm{TiO}_{2}$ nanotubes was not changed. The surface of the $\mathrm{TiO}_{2} \mathrm{NTs}$ photoelectrode was covered with a non-uniform flake-shaped reduced graphene oxide film. The impedance of $\mathrm{RGO} / \mathrm{TiO}_{2}$ NTs was smaller than that of $\mathrm{TiO}_{2}$ NTs photoelectrode.

Author Contributions: Conceptualization, J.Z. and Y.L.; software, Z.X. and S.Y. (Shaodong Yang); formal analysis, Y.L.; investigation, S.Y. (Shaodong Yang); data curation, S.Y. (Shiyou Yu); methodology and writing — original draft preparation, S.Y. (Siying Yuan); writing-review and editing, C.T.; supervision, J.L.; resources, validation, project administration, and funding acquisition, J.Z. All authors have read and agreed to the published version of the manuscript.

Funding: This research was funded by Support Program for Young Innovative Talents in Colleges and Universities of Heilongjiang Province, grant number UNPYSCT-2018136.

Informed Consent Statement: Informed consent was obtained from all subjects involved in the study.

Conflicts of Interest: The funders had no role in the design of the study; in the collection, analyses, or interpretation of data; in the writing of the manuscript; or in the decision to publish the results.

\section{References}

1. King, T.C. Azo Dyes and Human Health: A Review; Taylor \& Francis: Washington, DC, USA, 2016; pp. $233-261$.

2. Wang, X.L.; Rong, X.; Lin, H.Y.; Liu, D.N.; Wang, X.; Liu, G.C.; Song, G. A series of novel polyoxometalate-based Ag I -complexes constructed from asymmetric pyridyl-monoamide ligand: Synthesis, structures and selective separation of cationic dyes. Inorg. Chim. Acta 2017, 461, 279-289. [CrossRef]

3. Zhu, M.T.; Kurniawan, T.A.; Song, F.; Ouyang, T.; Othman, M.H.D.; Rezakazemi, M.; Shirazian, S. Applicability of Ba$\mathrm{TiO}$ /graphene oxide (GO) composite for enhanced photodegradation of methylene blue (MB) in synthetic wastewater under UV-vis irradiation. Environ. Pollut. 2019, 255, 113182.

4. Reddy, B.S.; Ramana, K.V.; Ravindhranath, K. Extraction of methylene blue dye from polluted waters using some bio-adsorbents. Int. J. Appl. Biol. Pharm. Technol. 2012, 3, 215-224.

5. Bhattacharjee, C.; Dutta, S.; Saxena, V.K. A review on biosorptive removal of dyes and heavy metals from wastewater using watermelon rind as biosorbent. Environ. Adv. 2020, 2, 100007. [CrossRef]

6. Hussein, T.K.; Jasim, N.A. A comparison study between chemical coagulation and electro-coagulation processes for the treatment of wastewater containing reactive blue dye. Mater. Today Proc. 2021, 42, 1946-1950.

7. Khandelwal, N.; Tiwari, E.; Singh, N.; Marsac, R.; Schäfer, T.; Monikh, F.A.; Darbha, G.K. Impact of long-term storage of various redox-sensitive supported nanocomposites on their application in removal of dyes from wastewater: Mechanisms delineation through spectroscopic investigations. J. Hazard. Mater. 2021, 401, 123375. [CrossRef] [PubMed]

8. Anantha, M.S.; Jayanth, V.; Olivera, S.; Anarghya, D.; Venkatesh, K.; Jayanna, B.K.; Sachin, H.P.; Muralidhara, H.B. Microwave treated Bermuda grass as a novel photocatalyst for the treatment of methylene blue dye from wastewater. Environ. Nanotechnol. Monit. Manag. 2021, 15, 100447.

9. Espinola-Portilla, F.; Navarro-Mendoza, R.; Gutiérrez-Granados, S.; Morales-Muñoz, U.; Brillas-Coso, E.; Peralta-Hernández, J.M. A simple process for the deposition of $\mathrm{TiO}_{2}$ onto BDD by electrophoresis and its application to the photoelectrocatalysis of Acid Blue 80 dye. J. Electroanal. Chem. 2017, 802, 57-63. [CrossRef]

10. Garcia-Segura, S.; Brillas, E. Applied photoelectrocatalysis on the degradation of organic pollutants in wastewaters. J. Photochem. Photobiol. C Photochem. Rev. 2017, 31, 1-35. [CrossRef]

11. Licht, S.; Wang, B.; Mukerji, S.; Soga, T.; Umeno, M.; Tributsch, H. ChemInform Abstract: Efficient Solar Water Splitting, Exemplified by $\mathrm{RuO}_{2}$-Catalyzed AlGaAs/Si Photoelectrolysis. Chem. Inform. 2001, 104, 8920-8924. [CrossRef]

12. Zhang, Y.; Xiong, X.; Han, Y.; Zhang, X.; Shen, F.; Deng, S.; Xiao, H.; Yang, X.; Yang, G.; Peng, H. Photoelectrocatalytic degradation of recalcitrant organic pollutants using $\mathrm{TiO}_{2}$ film electrodes: An overview. Chemosphere 2012, 88, 145-154. [CrossRef]

13. Ye, S.; Chen, Y.; Yao, X.; Zhang, J. Simultaneous removal of organic pollutants and heavy metals in wastewater by photoelectrocatalysis: A review. Chemosphere 2021, 273, 128503. [CrossRef] [PubMed]

14. Fujishima, A.; Honda, K. Electrochemical photolysis of water at a semiconductor electrode. Nature 1972, 238, 37-38. [CrossRef]

15. Gupta, S.M.; Tripathi, M. A review of $\mathrm{TiO}_{2}$ nanoparticles. Chin. Sci. Bull. 2011, 56, 1639. [CrossRef]

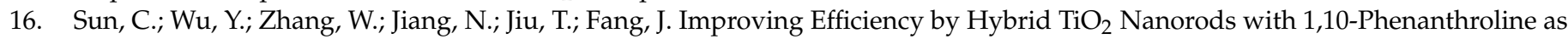
A Cathode Buffer Layer for Inverted Organic Solar Cells. ACS Appl. Mater. Interfaces 2013, 6, 739-744. [CrossRef] [PubMed] 
17. Yang, H.G.; Sun, C.H.; Qiao, S.Z.; Zou, J.; Liu, G.; Smith, S.C.; Cheng, H.M.; Lu, G.Q. Anatase TiO 2 single crystals with a large percentage of reactive facets. Nature 2008, 453, 638. [CrossRef] [PubMed]

18. Mena, E.; José, M.D.V.M.; Mesones, S.; Marugán, J. Influence of anodization mode on the morphology and photocatalytic activity of $\mathrm{TiO}_{2}$-NTs array large size electrodes. Catal. Today 2017, 313, 33-39. [CrossRef]

19. Adachi, M.; Murata, Y.; Harada, M.; Yoshikawa, S. ChemInform Abstract: Formation of Titania Nanotubes with High PhotoCatalytic Activity. Chem. Inform. 2000, 31, 942-943. [CrossRef]

20. Chu, S.Z.; Inoue, S.; Wada, K.; Li, D.; Awatsu, S. Highly Porous $\left(\mathrm{TiO}_{2}-\mathrm{SiO}_{2}-\mathrm{TeO}_{2}\right) / \mathrm{Al}_{2} \mathrm{O}_{3} / \mathrm{TiO}_{2}$ Composite Nanostructures on Glass with Enhanced Photocatalysis Fabricated by Anodization and Sol-Gel Process. Chem. Inform. 2003, 107, 6586-6589. [CrossRef]

21. Zhang, Z.; Yuan, Y.; Fang, Y.; Liang, L.; Ding, H.; Shi, G.; Jin, L. Photoelectrochemical oxidation behavior of methanol on highly ordered TiO2 nanotube array electrodes. J. Electroanal. Chem. 2007, 610, 179-185. [CrossRef]

22. Jeon, M.S.; Chun, Y.G.; Chang, S.J.; Kim, J.H.; Kang, B. Formation of Titania Nanotubes and Application for Dye-Sensitized Solar Cell. J. Electrochem. Soc. 2003, 150, G488.

23. Mor, G.; Shankar, K.; Varghese, O.; Grimes, C. Photoelectrochemical properties of titania nanotubes. J. Mater. Res. 2004, 19, 2989-2996. [CrossRef]

24. Chakraborty, I.; Chatterjee, S.; Ayyub, P. Field emission from hydrogen titanate nanotubes. Appl. Phys. Lett. 2011, 99, 1179. [CrossRef]

25. Mor, G.K.; Varghese, O.K.; Paulose, M.; Shankar, K.; Grimes, C.A. A Review on Highly Ordered, Vertically Oriented TiO 2 Nanotube Arrays: Fabrication, Material Properties, and Solar Energy Applications. Sol. Energy Mater. Sol. Cells 2006, 90, 2011-2075. [CrossRef]

26. Li, L.; Zhou, Z.; Lei, J.; He, J.; Zhang, S.; Pan, F. Highly ordered anodic $\mathrm{TiO}_{2}$ nanotube arrays and their stabilities as photo(electro)catalysts. Appl. Surf. Sci. 2012, 258, 3647-3651. [CrossRef]

27. Cao, D.; Wang, Q.; Liu, Z.; Zhang, H.; Gao, S. Enhanced the photoelectrocatalytic performance of $\mathrm{TiO}_{2}$ nanotube arrays by the synergistic sensitization of Ag-AgBr nanospheres. Spectrochim. Acta Part A Mol. Biomol. Spectrosc. 2019, 227, 117674. [CrossRef]

28. Maryline, N.; Sébastien, B.; Cynthia, E.; Roland, H.; Philippe, M.; Mikhael, B. Enhanced Visible-Light Photocatalytic Performance of Electrospun rGO/ $\mathrm{TiO}_{2}$ Composite Nanofibers. J. Phys. Chem. C 2017, 121, 261-269.

29. Zhang, Y.; Hu, H.; Kang, W.; Qiu, G.; Liang, R.; Deng, L.; Yuan, H. Enhancing hydrogen evolution by photoelectrocatalysis of water splitting over a CdS flowers-loaded $\mathrm{TiO}_{2}$ nanotube array film on the Ti foil substrate. Ceram. Int. 2020, 46, 17606-17613. [CrossRef]

30. Lavanya, T.; Satheesh, K.; Dutta, M.; Victor Jaya, N.; Fukata, N. Superior photocatalytic performance of reduced graphene oxide wrapped electrospun anatase mesoporous $\mathrm{TiO}_{2}$ nanofibers. J. Alloys Compd. 2014, 615, 643-650. [CrossRef]

31. Nainani, R.K.; Thakur, P. Facile synthesis of $\mathrm{TiO}_{2}-\mathrm{RGO}$ composite with enhanced performance for the photocatalytic mineralization of organic pollutants. Water Sci. Technol. 2016, 73, 1927-1936. [CrossRef]

32. Fan, W.; Lai, Q.; Zhang, Q.; Wang, Y. Nanocomposites of $\mathrm{TiO}_{(2)}$ and Reduced Graphene Oxide as Efficient Photocatalysts for Hydrogen Evolution. J. Phys. Chem. C 2011, 115, 10694-10701. [CrossRef]

33. Jiang, G.; Lin, Z.; Chen, C.; Zhu, L.; Chang, Q.; Wang, N.; Wei, W.; Tang, $\mathrm{H}_{\text {. }} \mathrm{TiO}_{2}$ nanoparticles assembled on graphene oxide nanosheets with high photocatalytic activity for removal of pollutants. Carbon 2011, 49, 2693-2701. [CrossRef]

34. Bezerra, M.A.; Santelli, R.E.; Oliveira, E.P.; Villar, L.S.; Escaleira, L.A. Response surface methodology (RSM) as a tool for optimization in analytical chemistry. Talanta 2008, 76, 965-977. [CrossRef]

35. Box, G.; Behnken, D.W. Some New Three Level Designs for the Study of Quantitative Variables. Technometrics 1960, 2, 455-475. [CrossRef]

36. Zuo, J.L.; Li, Y.W.; Li, J.S.; Xia, Z.; Tan, C.; Jiang, L.M.; Sun, Y.Q.; Tian, S.L. Optimizedpreparation of TiO $2-\mathrm{NTs}_{2}$ photoelectrode by response surface method and its property of photocatalytic degradation. Res. Environ. Sci. 2020, 33, 677-684.

37. Gao, G.Y.; Guo, D.J.; Li, H.L. Electrocatalytic oxidation of formaldehyde on palladium nanoparticles supported on multi-walled carbon nanotubes-ScienceDirect. J. Power Sources 2006, 162, 1094-1098. [CrossRef]

38. Tian, G.; Fu, H.; Jing, L.; Xin, B.; Pan, K. Preparation and Characterization of Stable Biphase TiO 2 Photocatalyst with High Crystallinity, Large Surface Area, and Enhanced Photoactivity. J. Phys. Chem. C 2008, 112, 3083-3089. [CrossRef]

39. Zickler, G.A.; Smarsly, B.; Gierlinger, N.; Peterlik, H.; Paris, O. A reconsideration of the relationship between the crystallite size La of carbons determined by X-ray diffraction and Raman spectroscopy. Carbon 2006, 44, 3239-3246. [CrossRef] 